\title{
Ethnic Auto-And Hetero-Stereotypes of Representatives of the Indigenous Population and Immigrants in the Contemporary Metropolis
}

\author{
Elena Alekseevna Petrova ${ }^{1}$, Tatyana Ivanovna Bonkalo ${ }^{1}$, Elena Aleksandrovna Orlova ${ }^{1}$, Igor Anatolyevich \\ Panarin $^{1} \&$ Yuriy Vasilyevich Furman ${ }^{1}$ \\ ${ }^{1}$ Russian State Social University, 4, 1, V. Pika, Moscow, Russian Federation \\ Correspondence: Elena Alekseevna Petrova, Russian State Social University, 4, 1, V. Pika, Moscow, 129226, \\ Russian Federation. E-mail: lena-krukova@ya.ru
}

Received: August 25, 2014 Accepted: September 10, 2014 Online Published: November 27, 2014

doi:10.5539/ass.v10n24p263 URL: http://dx.doi.org/10.5539/ass.v10n24p263

\begin{abstract}
This article presents the results of an empirical study dedicated to identifying the specific features of auto-and hetero-stereotypes of indigenous community of Moscow and the immigrants from the North Caucasus and Central Asia. The authors carry out a theoretical analysis of contemporary researches on the problem of interethnic relations and ethnic tension, substantiate the topical character of the study, and determine the diagnostic tools applied to the studies of influence that the perception of the indigenous population of Moscow of their nation, and the nations of newly arrived immigrants would have on general inter-ethnic climate of the modern metropolis.
\end{abstract}

Keywords: ethnic stereotypes, interethnic relations, ethnic tension

\section{Introduction}

\subsection{Introduce the Problem}

One of the most urgent problems of the modern world is the growth of ethnic tensions, which is evidenced by the recent events occurred in several countries within the former Soviet Union and beyond, and related to nationality conflicts.

In connection with this there are a growing number of scientific researches dedicated to the problem of inter-ethnic and inter-confessional relations lately (Banks, 1996; Elchardus \& Spruyt, 2014; Harris, 1998; Schaafsma \& Williams, 2012).

Thus, M. Elchardus and B. Spruyt (2014) have investigated the problem of expansion of anti-Muslim sentiment in the world. J. Schaafsma and K. D. Williams (2012), disclosing the nature of religious fundamentalism, explore mechanisms of formation of intergroup hostility, introducing into the scientific vocabulary the terming of "exclusion" and studying its socio-psychological factors.

Lately the researches on inter-ethnic environment in Russia have intensified (Berry et al., 1990; Ensel \& Lin, 1991; Furnham \& Bechner, 1986; Giddens, 2000). For instance, dedicate his works to the problem of post-Soviet identity (Foxall, 2013); R. M. Shamionov, M. V. Grigoryeva, and N. V. Usova (2013) undertake the comparative analysis of the subjective well-being of Russian migrants in Spain and the foreigners in Russia.

The problem of interethnic relations is connected with the problem of personal tolerance/intolerance, and the researchers focus themselves on the essential conceptual and procedural dynamic characteristics of this socio-psychological phenomenon. In this respect the research undertaken by G. Kozhukhar (2013) is of great interest. The author explores the predictors of interpersonal tolerance among the psychology students, considering the basic assumptions as the dominating ones.

The inter-ethnic problem is also related to the issues of inter-cultural communication and integration.

R. Contini (2013) observes the development trends in the modern polyethnic society and explores the phenomenon of intercultural integration. A Michael A. Zárate, Moira Shaw, Jorge A. Marquez, and David Biagas Jr. (2012) investigate the effect of cultural exchange and its influence on intergroup relations and the self-concept 
of its subjects.

The problem of interethnic relations implies therefore solution of the number of urgent and complicated tasks: disclosure of its nature and substance, genesis and factors of interpersonal relationship among representatives of different nationalities, regularities and development factors of interethnic conflicts, and the effective prerequisites for their regulation.

\subsection{Specification of Problem}

The modern interdisciplinary scientific researches understand the interethnic relations as the social process; social model of the society, self-developing and self-regulating organization, intercultural communications, interethnic communications, interethnic cooperation. In the domestic scientific literature the interethnic relations are understood as the interaction between representatives of different ethnic groups with each other; relationship between the groups and the attitude towards the groups.

On the whole, the ethnic relations are defined as the dynamically changing system of interaction between the ethnic groups which is passing through certain stages during its development.

Our analysis of different models of development of interethnic relations allows us to claim that the most important variables mediating the features of the development of these relations shall be the following:

- the actors, the types of different alternative open actions, types of expectations, interdependency of actors and its actions, principles of rationality, modeling of a situation, modeling of the basis of communication procedure;

- the specifics of relationship between the ethnic groups by principle "minority-majority";

- the dynamics of ethnical identity;

- social status of the ethnic group (dominating or non-dominating ethnic group, the host society or immigrants) (Berry et al., 1990).

One of the dominating factors of interethnic tension in interethnic relationships is the ethnic and interethnic attitudes of their subjects. G. Allport, when systemizing various concepts of psychological matter and nature of an attitude, gives its definition as the state of consciousness and nervous system expressing willingness towards a certain action. According to the tradition, the attitude structure consists of consciousness, evaluation and willingness to act.

The ethnic attitude is therefore a type of a social attitude which determines a level of consciousness, evaluation and actions of a person included into a certain ethnic group; the interethnic attitude is the posture to interaction with other ethnic groups in different living environment, as well as the collaboration or opposition towards them.

The development of interethnic relationship is increasingly accompanied by the interethnic tension and conflicts. As a rule, the origin of the interethnic conflicts lies in ethno-psychological (the threat of the violent destruction of the habitual lifestyle, material and spiritual culture), socio-economic (the actual socio-economic inequality, or imaginary discrimination and the dominance of economic interests of certain ethnic groups), political (the ambitions of the political leaders), socio-cultural (the essential socio-cultural discrepancies) factors. Lately the interethnic conflicts have been increasingly replaced by the interfaith ones.

Among the recent studies it also stands to mention those works dedicated expressly to the problem of relationship between immigrants and the indigenous population (Gans, 1976; Turner \& Roszel, 1994).

In Russia, as well as in a number of countries within the former Soviet Union and beyond, the above problem appears to be very significant and topical. The efficiency of reducing of ethnic tension and the successful regulation of interethnic conflicts shall depend on its solution. At the present time the problem of interethnic relations between the immigrants and the indigenous population requires the thorough and constructive study and the following development on this basis of the clear program of practical actions towards reducing the social and psychological risks in interethnic relations.

Our country is characterized by a very special paradox situation with the ethnic migrations. On one hand, the number of former union republics (mostly the Caucasus and Central Asia) have begun and still actively keep on "driving out" of Russian and Russian speaking representatives (which is an original ethnocide). On the other hand, the representatives of local ethnos are massively moving to Russia.

Recently, the number of Georgian Diaspora in Moscow has increased more than four times, the Tajik and Uzbek diasporas-not less than 15 times, and the Chinese and Azerbaijan-dozens of times. The third part of population of Azerbaijan has moved to Russia. In Europe such processes have been named "the migration tsunami".

According to unofficial data, the number of immigrants in Moscow and Moscow region has already increased 
$16 \%$. It has been calculated that the increase in number of migrant workers by $0,5 \%$ shall decrease the salary of the indigenous population by more than $1 \%$. Thus, there is also the economical component in the immigration problem. The prediction for 2050 says that the number of immigrants and their descendants may by then exceed the third part of the country's population.

\section{Method}

An important role in determination of the nature of international relations and their intensity belongs to ethnic stereotypes, which represent a simplified and emotionally charged image of representatives of a certain nation. Awareness of the distinctive features of one's owns ethnic group (ethnic peculiarities of culture and identity) forms the auto-stereotypes, and the idea of the features of another ethnic group forms the hetero-stereotypes. T. A. Ovsyannikova (2004) provides a definition of general system of auto-stereotypes and hetero-stereotypes as the "ethnical status".

One of the indices of the ethnic status shall also be a degree of one's identification with their ethnic community: the more completely and closer that the individuals should identify themselves with their ethnic group and its auto-stereotypes, the higher shall be the ethnic status of this community. The proceedings of J. Kelly (2000) highlight a tendency for attribution of merits for any positive developments to the representatives of one's own group, and the guilt for any negative-to a stranger group.

For the purpose of revealing the peculiarities of ethnic stereotypes of indigenous people and immigrants in the modern metropolis there have been conducted an empirical study, with participation of 1875 young people representing the indigenous population of Moscow city, and 1245 of immigrants representing the "risk-causing" ethnic groups.

The study has been conducted on the basis of a complex of methods comprising the questionnaire methods (questionnaire, interviewing, survey), testing, projective methods, semantic differential; the results of the survey and the psycho-diagnostic quizzes elaborated by the authors have formed the stimulus material.

\section{Results}

\subsection{The Results of the First Stage}

The first stage of this research consisted in the respondent quiz, the results of which were considered both as a separate factual material for qualitative and quantitative analysis, as well as the incentive material to the semantic differential method that have been used in further research. According to the quiz, the "risk-causing" ethnic groups are those of the North Caucasus (33.8\%), Central Asia (31.6\%) and Transcaucasus region (20.9\%).

During the quiz the respondents named the typical personal qualities of such "risk-causing" ethnic groups, and these qualities were later on used as a base for composition of pairs of antonymous adjectives. The respondents were asked to estimate these personal qualities from the point of degree of their manifestation in themselves, and in the representatives of various ethnic groups. The findings have showed that the hetero-stereotypes are mostly negative pole (-1.6), unlike the auto-stereotype content which is characterized by a general positive tendency (1.4). Thus, the North Caucasus immigrants have been perceived by Moscow indigenous as the strangers $(6.8 \pm$ $0.4)$, angry (6.4 \pm 0.4$)$, hot-tempered $(6.8 \pm 0.5)$, rude $(6.2 \pm 0.6)$, dangerous $(6.6 \pm 0.6)$, conceited $(6.2 \pm 0.4)$, cunning (5.9 \pm 0.4$)$, unpredictable (5.6 \pm 0.5$)$; the representatives of Central Asia-strangers ( $6.7 \pm 0.7)$, primitive $(6.3 \pm 0.6)$, untidy $(6.8 \pm 0.7)$, coward $(6.0 \pm 0.6)$, foolish $(6.5 \pm 0.7)$, week $(5.4 \pm 0.5)$, but also hard-working $(5.2 \pm 0.5)$, polite $(4.9 \pm 0.5)$ and obliging $(4.8 \pm 0.5)$. When giving characteristics to their own ethnic group, the respondents have been highlighting such personal qualities as one's native $(6.9 \pm 0.7)$, kind $(6.3 \pm 0.6)$, clever $(5.5 \pm 0.5)$, good $(5.9 \pm 0.6)$, fair $(5.4 \pm 0.5)$, respectful $(4.7 \pm 0.5)$, although also lazy $(4.2 \pm 0.4)$ and unpredictable $(4.4 \pm 0.5)$. It is remarkable that the first place in order of importance were given to the index "Us-Them" (native-stranger), which evidences the clear awareness of the border which exists between one's own and the other represented ethnic groups, and the unwillingness to ever loosen it.

\subsection{The Results of the Content Analysis}

The results of the content analysis of respondents' answers have also showed that the most relevant characteristics of the immigrants suggested by the indigenous population shall be their moral qualities. With this the lack of evidence of conventional moral qualities in the immigrants' behaviour shall lead to the increasing of ethnic tension and social distance between the two parties, and to reducing of ethnic tolerance, escalation of nationalist manifestations and immigrant-phobia on behalf of the host party.

The elicited fact of this absolute priority of influence of moral and ethical qualities of interacting parties on the character of their interethnic relations, may be explained as follows. In psychology the moral qualities are 
considered as the indicators that characterize the psychologically mature and socially responsible persona. They are generally defined as "a manifestation of the "inner man" through manners and behavior," as moral norms and principles which became the inner motives of behavior and which determine the usual forms of this behavior. There are some studies which, in particular, substantiate the dependence of structure, genesis and determinants of the moral consciousness on ethnic and cultural factors, which implies the possibility of developing the fundamentally different types of moral consciousness in different cultures (Karandashev et al., 2008). It may lead to inadequate perception and interpretation of certain forms of behaviour by different ethnic groups. One can find the corroboration of such opinion, for example, in the research of Z. M. Gadzhimuradova, who had studied the ethnic identity in the case of Dagestan people. The author has revealed a high degree of the particularism among the Dagestan youth, which allows them using the inherently different moral principles for "us" and "them" (that feature is missing among the Russian youth), and the traditionalism that ensures the preservation of their ethnic identity with relevant phenomenon of "double standards" (Gadzhimuradova \& Khvostov, 2005).

Our study has revealed that the majority of representatives of the host party are constantly suffering from the unfavorable, stressful situations caused by their inter-ethnic interaction with immigrants. According to the works of Ch. Spilberger, a stressful situation causes anxiety which is intensified as the perceived level of threat is increasing (Khvostov, 2005). The state of anxiety, as a rule, brings a person to use their self-control mechanisms, or the defense mechanisms manifesting in aggression. This leads to a vicious circle-the "aggressive complex" of immigrants, caused by the frustration of vital needs, and the prevailing negative attitude of the host party towards immigrants instigate the both parties to apply to various forms of protective aggressive behavior.

We can find the confirmation of the above in respondents' answers in connection with possible reasons for ethnic tension in interaction with the immigrants. These are: the immigrants' aggression (70\%), the behavioural practices that do not comply with the country's culture (66.5\%) and the aggravation of criminal situation (50\%).

The quiz has also found out opinions of the host party on the factors contributing to the increase of ethnic tension in relations with the immigrants. The analysis of the obtained data has showed that for the majority of respondents the dominating factor that increases the level of interethnic tension in interactions of titular population with the immigrants is the intensive growth of number of immigrants in Russia (70\%). The second relevant factor indicated by the respondents was the conflicts in the republics of Northern Caucasus $(60 \%)$.

\subsection{The Results of Determine the Level of Socio-psychological Mutual Acceptance by the Indigenous Population and the Immigrants}

To determine the level of socio-psychological mutual acceptance by the indigenous population and the immigrants, we have used the "Scale of social distance" of E. Bogardus, modification L. G. Pochebut (2005).

According to the obtained data, the positive zone of choice includes such ethnos as: Russian $+0,816$, which evidence the high level of acceptance, pursuit of integration, affinity, tolerant attitude towards other representatives of one's own ethnos. Also, the positive zone has included: the Ukrainian $+0,377$ and Belarusian $+0,149$. Since the index of real social acceptability is positive, but $<50 \%$ of possible social acceptability, it can be interpreted as the willing of the native-born Russian-speaking population of Moscow region to maintain if possible only the superficial, formal contacts with representatives of Ukrainian and Belarusian ethnos, with a general rather positive attitude towards them.

The three anti-leaders of social acceptance for the titular population are the representatives of such ethnic groups as Tajiks, Chechens and Dagestanis.

Thus, the identified maximal distance between representatives of the indigenous population and immigrants-representatives of the above ethnic groups, evidence the high level of intolerance of the host party, and its pursuit of segregation and isolation.

\subsection{Ethnic Stereotypes of Immigrants}

The next step of our empirical study suggested the investigative work with immigrant respondents. In particular, there has been conducted a survey with the purpose to identify their concepts of the interethnic relations with representatives of the titular population. This survey has also given information about the possible motives for migration, as well as about some life goals connected with the migration.

The survey was conducted among the representatives of ethnic groups from regions of Northern Caucasus, Central Asia and Transcaucasus. After the quantitative and qualitative processing of the obtained results it can be resumed as follows. 
The highest socio-economic status belongs to the representatives of ethnic groups of Northern Caucasus. These immigrants are characterized by high educational level: around $45.6 \%$ of respondents have higher (legal, construction etc.) education, and $24,3 \%$-secondary specialized education. The type of activities of $65 \%$ of respondents (construction and business sector, government institutions-mainly the law enforcement authorities) provides them with a rather high income. $80 \%$ of respondents are either renting a flat or living with their relatives.

Due to a rather high socio-economical status $40 \%$ of immigrants from this region indicate the "career building" among the main motives for migration (permanent as well as temporary), almost the same number of respondents have named the improvement of the material position, $14 \%$ have such prevailing motive for migration into the Moscow region as "prestige", and 16\% explain their migration by the "terrorist actions" (i.e. pursuit of safety).

Thus, it can be concluded that more than a half of immigrants from Northern Caucasus aim to personal fulfillment, prestige, social recognition, however, this aim often faces the negative attitude from the part of indigenous population, which leads to the intra- and interpersonal conflicts.

We have detected that the lowest socio-economic status belongs to representatives of ethnic groups of Central Asia (Tajiks, Uzbeks and Kyrgyz). Firstly, it should be noted that the young immigrants from this region are characterized by a low educational and professional qualification levels. Thus, according to the conducted analysis, $71.4 \%$ of immigrants have not completed the secondary school education (9-10 forms); $14.3 \%$ of respondents have higher education and other 14.3\%-6-7 forms of a secondary school. Among overall number of immigrants of these ethnic groups $28.6 \%$ do not have any profession, the same number of respondents $(28.6 \%)$ have been working as shepherds and sheep men. Many young Tajiks explain migration by the unwillingness to do their military service. The basic type of activities of $85 \%$ of respondents is the low-skilled labor in construction and building, at the objects of municipal facilities, in commerce. The living conditions of most of the immigrants are below average.

We believe that this low level of socio-economical status of these immigrants has determined the main motive for their migration- $93 \%$ representatives of these ethnic groups name as such motive the improvement of the material position for themselves and for their families.

It has been noted in a number of cross-cultural investigations (Furnham \& Bochner, 1986; Soldatova \& Shajgerova, 2001) that the low levels of socio-economical status, rural origins, lack of education, the expressed religiosity, traditionalism have negative influence in particular on the psychosomatic health of the immigrants and on the level of their socio-psychological adaptation on the whole. We have empirically detected that such statement is especially true for the immigrants from the Central Asia who have participated in the survey.

We have found out that in connection with such personal characteristics as "optimism", reflecting the willingness to fix oneself on the ways of solution rather than on problems themselves, belief in success, and as "tolerance to the ambiguity", which implies the easy attitude to the lack of clear information about various situations, lack of certainty in the goals and expectations, there are the significant discrepancies between the representatives of the host party and the immigrants.

\section{Discussion}

Therefore it can be stated that such small manifestation of optimism and tolerance to the ambiguity influence significantly on immigrants' addictiveness, not allowing to perform actions intended to neutralization or confronting the stressful circumstances.

The recent analysis has allowed identifying the most common motives of migration: the motive of "pursuit of a "better life"; the motive of "envy"; the motive of "inferiority complex"; the motive of personal fulfillment; the security motive; political motives.

Migration may incur positive (demographical, economical) as well as the negative consequences. However, many authors focusing on the negative consequences most frequently point out the following:

- for the immigrants-socio-psychological disadaptation, emotional and psychosomatic disorders, "cultural shock" etc.;

- for the host party-violation of group identity; social tension, ethnical conflicts, as well as criminal and other negative manifestations; provoking extremist movements.

We have detected the most frequent deficits among immigrants in the new social environment, which serves as the "launchers" of actualization of social and psychological risks in the interethnic relations: 
a) cognitive deficits-the lack or absence of cognitive references for evaluation of certain factors of the new environment, and therefore the mistaken interpretation of these factors, impossibility to develop their prompt and quality evaluation and relevant feeling of uncertainty;

б) social deficits-ignorance of the new social and cultural regulations, of the language (or the poor knowledge), unawareness of the restrictions and prohibitions regulating the daily living of an immigrant;

в) behaviourial deficits-application of ineffective former developed behaviourial strategies which do not comply partly or in whole to the new conditions;

г) psychological and physiological deficits-violation of the dynamic living stereotype of an individual in view of the novelty of living conditions, change of time zone, temporary unsatisfaction of some basic requirements of an immigrant;

д) informational deficits-information overloading, when there is a difficulty of interpretation of the importance of received new diverse information;

e) emotional deficits-negative emotions, depressions, domestic isolation, lack of the emotional support etc.;

ж) existential deficits-feelings (often temporary) of loss of reason to live, loss of balance of mind, neurotic depressions due to the unmet expectations.

\section{Conclusion}

Having found themselves in the new socio-cultural environment, in the process of interaction with the host party the immigrants almost always face the complex of problems caused by the differences in traditions, customs, attitudes, behavior, value orientation, formed under different cultural conditions.

In turn, the particularity of immigrants causes confusion and irritation in the titular population, which often leads to mutual inter-ethnic intolerance and conflicts. The surge of migration in the recent years in Russia has contributed to the development of a new social phenomenon-migrantophobia. Migrantophobia forms an important socio-psychological factor that intensifies the processes of intergroup mobilization among the immigrants which results in the increase of social tension within the society.

The youth of the host society often create their sub-culture towards immigrants resulting in the informal unions and groups of sometimes nationalistic, extremist character, which leads to the confrontations and crimes on ethnic grounds as evidenced by the statistics of the recent years.

Such facts significantly reduce the possibility of integration of immigrants and the titular population.

Thus, the substance of the auto- and hetero-stereotypes of representatives of the indigenous population and the immigrants is becoming one of the dominant factors for the escalation of ethnic tension in the contemporary metropolis

\section{References}

Banks, M. (1996). Ethnicity: Anthropological Constructions. London.-New York.

Berry, J. W., Poortinga, Y. N., Segall, M. N., \& Dasen, P. R. (1990). Cross-cultural psychology: Research and application. New York.

Contini, R. M. (2013). New Generations and Intercultural Integration in a Multi-ethnic Society. Procedia-Social and Behavioral Sciences, 93, 1819-1829. http://dx.doi.org/10.1016/j.sbspro.2013.10.124

Elchardus, M., \& Spruyt, B. (2014). Universalism and anti-Muslim sentiment. International Journal of Intercultural Relations, 38, 75-85. http://dx.doi.org/10.1016/j.jintrel.2013.03.001

Ensel, W. M., \& Lin, N. (1991). The life stress paradigm and psychological distress. The journal of health and social behavior, 32(4), 321-341. http://dx.doi.org/10.2307/2137101

Foxall, A. (2013). A contested landscape: Monuments, public memory, and post-Soviet identity in Stavropol', Russia. Communist and Post-Communist Studies, 46(1), 167-178. http://dx.doi.org/10.1016/j.postcomstud. 2012.12.012

Furnham, A., \& Bechner, S. (1986). Culture Shock: Psychologial reaction to unfamiliar environments. London. New York.

Gadzhimuradova, Z. M., \& Khvostov, A. A. (2005). Moral identity of the student youth of two cultures: Traditions of Dagestan and Russia: Monography. Moscow: Prometey. 
Gans, H. J. (1979). Symbolic ethnicity: The future of ethnic groups and cultures in America. Ethnic and Racial Studies, 2(1), 1-20. http://dx.doi.org/10.1080/01419870.1979.9993248

Giddens, A. (2000). Runaway World. How Globalization is Reshaping our Lives (p. 176). London.

Harris, M. A (1998). Special case of voluntary associations? Towards a theory of congregational organization. British Journal of Sociology, 49(4), 602-618. http://dx.doi.org/10.2307/591291

Karandashev, V. N., Lebedeva, M. M., \& Spilberger, C. (2008). The study of estimated anxiety. Moscow: Progress.

Kelly, J. (2000). The personality theory: Psychology of personal constructs. St. Petersbourgh: Rech.

Khvostov, A. A. (2005). Moral identity of a person: Structure, genesis, determinants: Monography. Moscow: MPGU.

Kozhukhar, G. (2013). Basic Assumptions as Predictors of Interpersonal Tolerance and Ethnic Identity in Psychology Students. Procedia-Social and Behavioral Sciences, 86, 511-517. http://dx.doi.org/10.1016/j. sbspro.2013.08.606

Michael, A. Z., Shaw, M., Marquez, J. A., \& Biagas, D. Jr. (2012). Cultural inertia: The effects of cultural change on intergroup relations and the self-concept. Journal of Experimental Social Psychology, 48(3), 634-645. http://dx.doi.org/10.1016/j.jesp.2011.12.014

Ovsyannikova, T. A. (2004). The problems of research on personal self-identity and ethnic identity. Maykop: MGTU.

Pochebut, L. G. (2005). Mutual understanding of cultures. Methodology and methods of ethnical and cross-cultural psychology. Psychology of interethnic tolerance. SPb.: Saint Petersburg State University.

Schaafsma, J., \& Williams, K. D. (2012). Exclusion, intergroup hostility, and religious fundamentalism. Journal of Experimental Social Psychology, 48(4), 829-837. http://dx.doi.org/10.1016/j.jesp.2012.02.015

Shamionov, R. M., Grigoryeva, M. V., \& Usova, N. V. (2013). The Subjective Well-being of Russian Migrants in Spain and of Foreigners in Russia. Procedia-Social and Behavioral Sciences, 86, 498-504. http://dx.doi.org/10.1016/j.sbspro.2013.08.604

Turner, R. J., \& Roszel, P. (1994). Psychosocial resources and the stress process. Stress and mental health. Contemporary issues and prospects for the future (pp. 179-210). New York: Plenum Press.

\section{Copyrights}

Copyright for this article is retained by the author(s), with first publication rights granted to the journal.

This is an open-access article distributed under the terms and conditions of the Creative Commons Attribution license (http://creativecommons.org/licenses/by/3.0/). 